\title{
Особенности фитолитных спектров степей и тундр Алтая
}

\section{Special aspects of steppe and tundra phytoliths spectra in the Altai Mountains}

\author{
Соломонова М. Ю., Силантьева М. М., Сперанская Н. Ю. \\ Solomonova M. Y., Silanteva M. M., Speranskaya N. Y. \\ Алтайский государственный университет, г. Барнаул, Россия. E-mail: solomonova@edu.asu.ru
}

Altai State University, Barnaul, Russia

\begin{abstract}
Peфepam. В статье приведены результаты сопоставления фитолитных спектров тундровых и степных растительных сообществ северного и северо-западного Алтая. Анализ проводился с учетом влияния климатических факторов: средняя месячная температура января, средняя месячная температура июля, среднее годовое количество осадков. Выявлено, что по многим морфотипам фитолитов спектры степей и тундр близки друг к другу, несмотря на различия по климатическим показателям территорий, на которых они формируются. Одним из морфотипов, позволяющих разделять фитолитные спектры тундр и степей, являются трапециевидные формы ронделей.
\end{abstract}

Ключевые слова. Почвы, Северный Алтай, степи, тундры, фитолитные спектры.

Summary. The article presents the results of comparison of phytoliths spectra of tundra and steppe plant communities on the Northern Altai. The analysis was carried out taking into account the influence of climatic factors: the average monthly temperature in January, the average monthly temperature in July, the average annual amount of precipitation. It has been revealed that in many morphotypes of phytoliths, the spectra of steppe and tundra are close to each other, despite the differences in climatic indicators of the territories in which they are formed. One of the morphotypes that allow the separation of phytolitic spectra of tundra and steppes are trapezoidal forms of the Rondels.

Key words. Northern Altai, phytoliths spectra, soil, steppe, tundra.

\section{Введение}

Кремневые частицы растений, фитолиты, являются основой многих палеоэкологических реконструкций. Фитолитный анализ широко используют для установления различных палеоэкологических параметров на территории тропических и субтропических широт земного шара (Albert et al., 2008; Bowdery, 1999; Bremond et al., 2008), а также для некоторых территорий Северной Америки и Китая (Blinnikov et al., 2001; Lu et al., 2006). Для умеренных широт Евразии метод успешно применяется в археологии и палеопочвоведении (Гаврилов, Гольева, 2014; Гольева, 1995, 2008; Занина и др., 2013; Кирюшин и др., 2013; Aseyeva et al., 2019; Wouters et al., 2019). Но все еще остается открытым актуальный вопрос возможности использования фитолитного анализа для реконструкции палеоклимата на этой территории (Solomonova et al., 2019).

Исследования климатической специфики отдельных фитолитных спектров растительных сообществ территории юга Западной Сибири показывают сложность выделения диагностических морфотипов фитолитов для разделения травянистых фитоценозов (Silantyeva et al., 2018; Solomonova et al., 2019). Сопоставление фитолитных спектров степей и тундр, находящихся в различных климатических горных поясах хребтов Алтайских гор, было проведено с целью показать влияние климатических факторов и геоботанических особенностей на формирование этих спектров.

\section{Материалы и методы}

Материалами для исследования послужили поверхностные пробы почв четырех степных сообществ и трех тундр северного и северо-западного Алтая (табл.). С каждой точки были отобраны пробы 
в трехкратной повторности. Обогащение проб фитолитами происходило по адаптированной методике А. А. Гольевой (Гольева, 2001; Solomonova et al., 2019). При микроскопировании образцов происходил подсчет отдельных морфотипов с учетом их деления на группы. Выборка частиц составила 500 штук по каждой пробе. Таким образом, был получен 21 фитолитный спектр по 7 фитоценозам. Анализ спектров проводился как по группам морфотипов, так и по их отдельным типам и подтипам согласно их геометрической форме и пропорциям (Solomonova et al., 2019).

Таблица

Характеристика местоположения и климата объектов исследования

\begin{tabular}{|c|c|c|c|c|}
\hline № & Название фитоценоза & Месторасположение & $\begin{array}{l}\text { Высота, } \\
\text { м н.у.м. }\end{array}$ & Климат* \\
\hline 1 & $\begin{array}{l}\text { Разнотравно-осочково-тырсоковыль- } \\
\text { ная настоящая степь }\end{array}$ & $\begin{array}{l}\text { Республика Алтай, долина р. } \\
\text { Бийка, хребет Куминские белки }\end{array}$ & 565 & $\begin{array}{l}\mathrm{T}_{1}-15,6^{\circ} \mathrm{C}, \\
\mathrm{T}_{7}+14,6^{\circ} \mathrm{C} \\
\mathrm{Oc}_{\text {год }} 380 \mathrm{MM}\end{array}$ \\
\hline 2 & $\begin{array}{l}\text { Закустаренная ковыльно-полынно-о- } \\
\text { сочковая луговая степь }\end{array}$ & $\begin{array}{l}\text { Республика Алтай, в } 350 \text { м от с. } \\
\text { Еланда, хребет Иолго }\end{array}$ & 471 & $\begin{array}{l}\mathrm{T}_{1}-15,8^{\circ} \mathrm{C}, \\
\mathrm{T}_{7}+14,9^{\circ} \mathrm{C} \\
\mathrm{Oc}_{\text {ro } 1} 360 \mathrm{MM}\end{array}$ \\
\hline 3 & Лишайниково-дриадовая тундра & $\begin{array}{l}\text { Республика Алтай, Семинский } \\
\text { хребет, г. Сарлык }\end{array}$ & 2343 & $\begin{array}{l}\mathrm{T}_{1}-18,5^{\circ} \mathrm{C}, \\
\mathrm{T}_{7}+10,5^{\circ} \mathrm{C} \\
\mathrm{Oc}_{\mathrm{ron}} 550 \mathrm{MM}\end{array}$ \\
\hline 4 & $\begin{array}{l}\text { Овсяницево-осочково-змеевиковая } \\
\text { тундра }\end{array}$ & $\begin{array}{l}\text { Республика Алтай, Семинский } \\
\text { хребет, г. Сарлык }\end{array}$ & 2360 & $\begin{array}{l}\mathrm{T}_{1}-18,5^{\circ} \mathrm{C}, \\
\mathrm{T}_{7}+10,5^{\circ} \mathrm{C} \\
\mathrm{Oc}_{\text {го }} 550 \mathrm{MM}\end{array}$ \\
\hline 5 & $\begin{array}{l}\text { Заболоченная ерниковая (ивово-бере- } \\
\text { зовая) разнотравно-осочковая тундра }\end{array}$ & $\begin{array}{l}\text { Республика Алтай, Семинский } \\
\text { хребет }\end{array}$ & 1994 & $\begin{array}{l}\mathrm{T}_{1}-18,3^{\circ} \mathrm{C}, \\
\mathrm{T}_{7}+10,6^{\circ} \mathrm{C} \\
\mathrm{Oc}_{\mathrm{rom}} 500 \mathrm{MM}\end{array}$ \\
\hline 6 & $\begin{array}{l}\text { Осочково-полынно-копеечниковая } \\
\text { петрофитная степь }\end{array}$ & Республика Алтай, хребет Иолго & 450 & $\begin{array}{c}\mathrm{T}_{1}-16,6^{\circ} \mathrm{C}, \\
\mathrm{T}_{7}+15,2^{\circ} \mathrm{C} \\
\mathrm{Oc}_{\text {ro }} 400 \mathrm{MM}\end{array}$ \\
\hline 7 & $\begin{array}{l}\text { Овсецово-володушково-осочковая } \\
\text { петрофитная луговая степь }\end{array}$ & $\begin{array}{l}\text { Алтайский край, Тигирекский } \\
\text { хребет }\end{array}$ & 747 & $\begin{array}{c}\mathrm{T}_{1}-16,2{ }^{\circ} \mathrm{C}, \\
\mathrm{T}_{7}+14,2^{\circ} \mathrm{C} \\
\mathrm{Oc}_{\text {го }} 620 \mathrm{MM}\end{array}$ \\
\hline
\end{tabular}

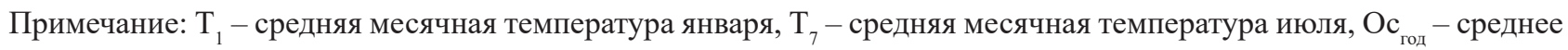
годовое количество осадков.

\section{Результаты и их обсуждения}

Исследования фитолитных спектров фитоценозов Алтайских гор показало, что состав фитолитов в спектрах степей и тундр отличается от комплексов кремниевых частиц, характеризующих другие типы растительности (Solomonova et al., 2019). В ходе анализа фитолитных спектров тундровых и степных поверхностных почв было выявлено то, что, несмотря на формирование этих сообществ в различных климатических условиях, обусловленных высотной поясностью, их спектры очень близки между собой (рис.). Тем не менее сопоставления этих спектров показало, что существует ряд форм, по которым они различаются.

При изучении фитолитного состава по дробной классификации морфотипов тундровых и степных почв выявлена близость спектров петрофитных, настоящих степей и тундр и отличия от них спектров луговой степи. Анализ классификации морофтипов на крупные группы показал, что спектры тундр близки к спектрам настоящей и луговой (рис.) степей.

Наиболее выраженными особенностями обладают фитолитные спектры петрофитных степей. Они отличаются от спектров тундр, настоящих и луговых степей по низкой сумме пузыревидных частиц и высокой доли настоящих двулопастных частиц. Идентифицировать этот вариант степей возможно по высокому числу волнистых пластинок, доля которых в спектрах петрофитных степей превосходит количество этого морфотипа в фитолитных комплексах других фитоценозов в 2-3 раза. 


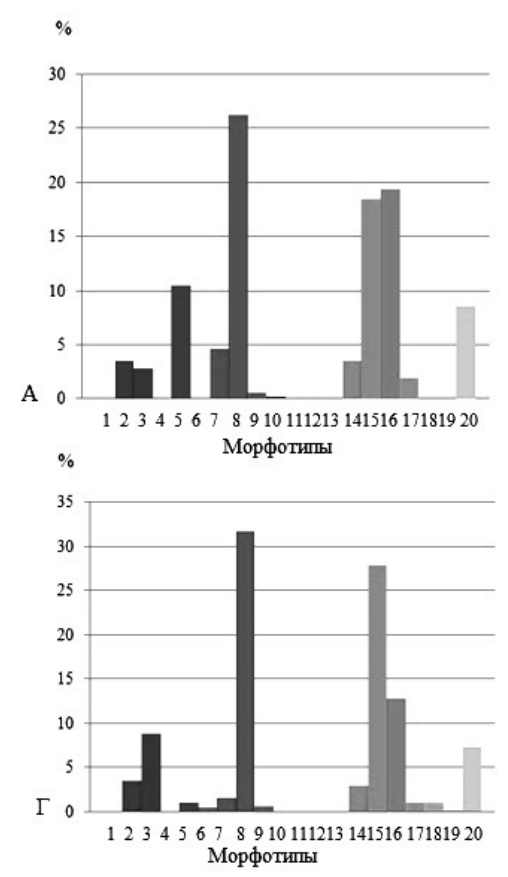

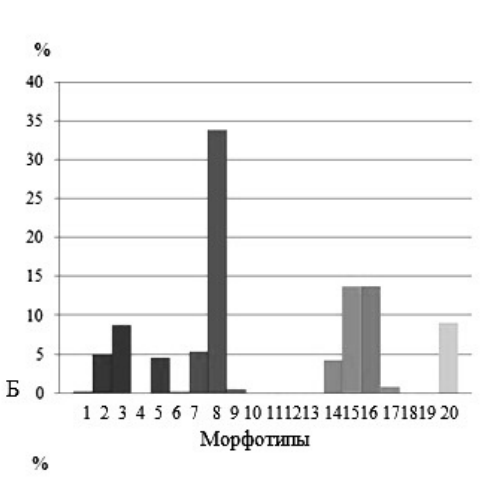

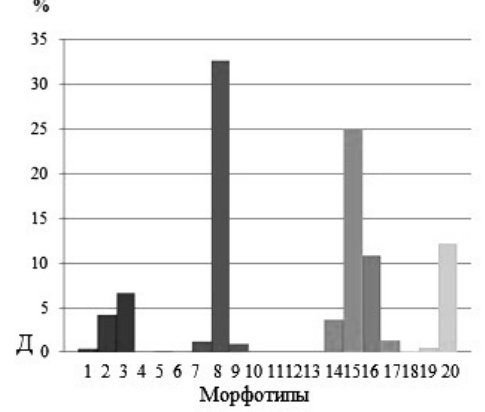

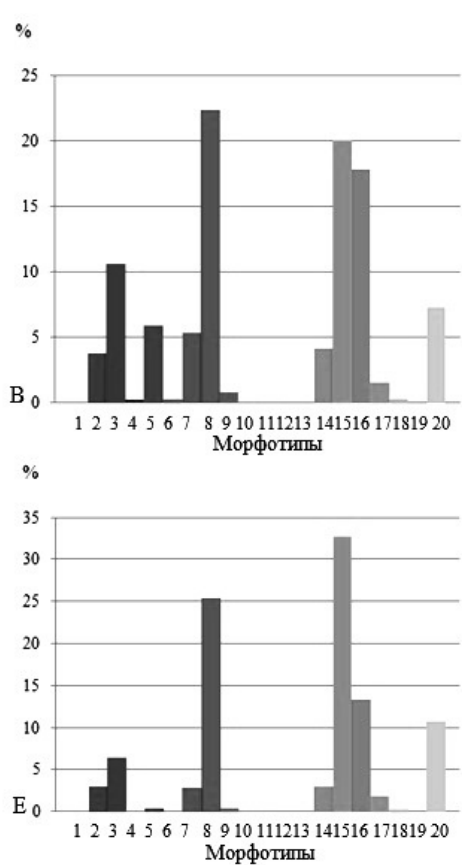

Рис. Примеры фитолитных спектров тундр и степей. Условные обозначения: А-B - спектры закустаренной ковыльно-полынно-осочковой луговой степи; Г-Е - спектры лишайниково-дриадовой тундры; 1 - пузыревидные частицы, 2 - волнистые пластинки, 3 - полилопастные трапециевидные частицы, 4 - седловидные частицы низкие, 5 - настоящие двулопастные частицы, 6 - крестовидные частицы, 7 - двулопастные частицы Stipa-типа, 8 сумма ронделей, 9 - конические папиллярные частицы осок, 10 - конические частицы с волнистым основанием, 11 - блочные структуры с порами, 12 - трахеиды хвойных, 13 - булавовидные клетки с выростами, 14 - сумма ланцетных частиц, 15 - сумма длинных частиц, 16 - сумма пластинок, 17 - глобулярные частицы, 18 - сферические гладкие частицы, 19 - инкрустационное окремнение, 20 - прочие формы фитолитов.

Наиболее важной группой морфотипов для почвенных проб исследованных растительных сообществ являются рондели. По сумме ронделей спектры всех изученных фитоценозов близки между собой. Самым распространенным типом ронделей является конический низкий. В наибольшем числе он представлен в спектрах настоящих и луговых степей. Несколько ниже количество фитолитов этого морфотипа в поверхностных почвах петрофитных степей. Фитолитные спектры тундр отличаются от спектров степей по высокому числу трапециевдных ронделей низких. Еще одним важным типом ронделей, несмотря на малую встречаемость, является килиевидный рондель с несколькими килями. По возрастанию количества этого морфотипа в спектрах можно построить следующий ряд: 1) петрофитные степи; 2) луговые степи и тундры; 3) настоящие степи. Таким образом, этот морфотип можно использовать для разграничения различных степных фитоценозов. В спектрах тундр в значительном числе представлен еще один подтип ронделей - седловидный.

Важным морфотипом в фитолитных исследованиях на территории умеренных широт являются ланцетные частицы (Гольева, 2001; Silantyeva et al., 2018). По низкому числу суммы ланцетных частиц спектры тундр отличаются от степных фитолитных спектров.

Среди длинных частиц важную роль играют округлые формы при отделении спектров настоящей степи от других вариантов степных сообществ. Длинные крупнозубчатые частицы являются диагностическими для спектров тундр, в остальных спектрах их количество сопоставимо.

\section{Заключение}

Фитолитные спектры степных и тундровых фитоценозов, формирующиеся в различных климатических условиях, близки между собой по большинству морфотипов. Тундровые спектры отличаются от степных составом отдельных форм ронделей. Среди степных фитоценозов наиболее специфичные спектры формируются в почвах петрофитных степей. 
Благодарности. Данные о климате территории предоставлены к. г. н. Н. Ф. Харламовой, доцентом кафедры физической географии и геоинформационных систем Алтайского государственного университета, за предоставление. Геоботанические описания растительных сообществ выполнены к. б. н. Н. В. Елесовой, доцентом кафедры ботаники Алтайского государственного университета. Исследование выполнено при финансовой поддержке РФФИ в рамках научного проекта № 17-04-00437 \19 «Влияние эколого-ценотических и климатических факторов на формирование фитолитных спектров основных фитоценозов Северного Алтая».

\section{ЛИТЕРАТУРА}

Гаврилов Д. А., Гольева $\boldsymbol{A}$. $\boldsymbol{A}$. Микробиоморфное исследование почв со вторым гумусовым горизонтом южно-таежной подзоны Западной Сибири // Вестник Томского государственного университета. Биология, 2014. - № 2 (26). - C. 7-24.

Гольева A. A. Микробиоморфная память почв // Память почв: Почва как память биосферно-геосферно-антропосферных взаимодействий / отв. ред. В. О. Таргульян, С. В. Горячкин. - М., 2008. - С. 500-524.

Гольева А. А. Опыт применения фитолитного анализа в почвоведении // Почвоведение, 1995. - № 12. - С. 1-6.

Гольева $\boldsymbol{A}$. $\boldsymbol{A}$. Фитолиты и их информационная роль в изучении природных и археологических объектов. - Москва - Сыктывкар: Элиста, Полтекс, 2001. - 140 с.

Занина О. Г., Тишкин А. А., Ходжаева А. К., Демкин В. А. Результаты фосфатного и биоморфного анализов грунтового заполнения сосуда из кургана № 4 памятника Бугры (Северо-Западные предгорья Алтая) // Теория и практика археологических исследований, 2013. - № 1(7). - С. 125-134.

Кирюшин К. Ю., Силантьева М. М., Ситников С. М., Семибратов В. П., Соломонова М. Ю., Сперанская $\boldsymbol{H}$. Ю. Комплексные археоботанические и фитолитные исследования на поселении Новоильинка-3 (Северная Кулунда) // Известия Алтайского государственного университета, 2013. - № 4-1 (80). - С. 156-164.

Albert R. M., Shahack-Gross R., Cabanes D., Gilboa A., Lev-Yadun S., Portillo M., Sharon I., Boaretto E., Weiner $\boldsymbol{S}$. Phytolith-rich layers from the Late Bronze and Iron Ages at Tel Dor (Israel): mode of formation and archaeological significance // Journal of Archaeological Science, 2008. - № 35. - P. 57-75.

Aseyeva E., Makeev A., Kurbanova F., Kust P., Rusakov A., Khokhlova O., Mihailov E., Puzanova T., Golyeva A. Paleolandscape reconstruction based on the study of a buried soil of the Bronze Age in the Broadleaf

forest area of the Russian plain // Geosciences, 2019. - № 9 (111). - P. 1-27

Blinnikov M., Busacca A., Whitlock C. A new 100,000-year phytolith record from the Columbia Basin, Washington, USA // Phytoliths: Applications in Earth Sciences and Human History / Meunier J. D., Colin F. (Eds.) - Lisse, 2001. - P. $27-55$.

Bowdery D. Phytoliths from tropical sediments: reports from Southeast Asia and Papua New Guinea // Bulletin of the Indo-Pacific Prehistory Association, 1999. - Vol. 18. - P. 159-168.

Bremond L., Alexandre A., Wooller M. J., Hély Ch., Williamson D., Schäfer P. A., Majule A., Guiot J. Phytolith indices as proxies of grass subfamilies on East African tropical mountains // Global and Planetary Change, 2008. - № 61. - P. 209-224.

Lu H. Y., Wu N. Q., Yang X. D., Jiang H., Liu K.-b., Liu T. Sh. Phytoliths as quantitative indicators for the reconstruction of past environmental conditions in China I: phytolith-based transfer functions // Quaternary Science Reviews, 2006. - № 25. - P. 945-959.

Silantyeva M., Solomonova M., Speranskaja N., Blinnikov M. S. Phytoliths of temperate forest-steppe: A case study from the Altay, Russia // Review of Palaeobotany and Palynology, 2018. - Vol. 250. - P. 1-15.

Solomonova M. Y., Blinnikov M. S., Silantieva M. M., Speranskaya N. Y. Influence of Moisture and Temperature Regimes on the Phytolith Assemblage Composition of Mountain Ecosystems of the Mid Latitudes: A Case Study From the Altay Mountains // Frontiers in Ecology and Evolution, 2019. DOI:10.3389/fevo.2019.00002.

Wouters B., Devos Y., Vrydaghs L., Ball T., De Winter N., Reygel P. An integrated micromorphological and phytolith study of urban soils and sediments from the Gallo-Roman town Atuatuca Tungrorum, Belgium // Geoarchaeology, 2019. - P. 1-19. 